Noncl osure techni que wi th sal i ne- coupl ed bi pol ar el ectrocaut ery in management of the cut surface after di stal pancreat ect omy

\begin{tabular}{|c|c|}
\hline 著者 & $\begin{array}{l}\text { K t agawa Hi r ohi sa, Oht a Tet suo, Tani Takashi, } \\
\text { Taj i ma Hi dehi ro, Nakagawar a Hi sat oshi, Ohni shi } \\
\text { I chi ro, Takamur a Hi royuki, Kayahar a Nasat o }\end{array}$ \\
\hline $\begin{array}{l}\text { jour nal or } \\
\text { publ i cat } \mathrm{i} \text { on } \mathrm{ti} \mathrm{tl} \mathrm{e}\end{array}$ & Jour nal of Hepat o- Bi I i ar y- Pancr eat i c Sur ger y \\
\hline vol une & 15 \\
\hline nunber & 4 \\
\hline page $r$ ange & 377- 383 \\
\hline year & 2008-08 01 \\
\hline URL & ht t p: //hdl . handl e. net /2297/19571 \\
\hline
\end{tabular}




\title{
Nonclosure technique with saline-coupled bipolar electrocautery in management of the cut surface after distal pancreatectomy
}

\author{
Hirohisa Kitagawa, Tetsuo Ohta, Takashi Tani, Hidehiro Tajima, Hisatoshi Nakagawara, Ichiro Ohnishi, \\ Hiroyuki Takamura, and Masato Kayahara \\ Department of Gastroenterologic Surgery, Graduate School of Medical Science, Kanazawa University, 13-1 Takaramachi, \\ Kanazawa 920-8641, Japan
}

\section{Abstract}

Background/Purpose. Management of the pancreatic remnant after distal pancreatectomy is still debated, the most serious complication is development of a pancreatic fistula. We developed a nonclosure technique with saline-coupled bipolar electrocautery for preventing fistula formation after distal pancreatectomy as an alternative to traditional stump closure methods.

Methods. The distinguishing feature of this technique is nonclosure of the stump, relying instead upon dependable ligation of the main pancreatic duct and sealing of the cut surface by shrinkage accomplished by low-temperature coagulation using saline-coupled bipolar electrocautery. A recent addition has been intraoperative stenting of the remnant pancreatic duct.

Results. To date we have used the nonclosure technique in 40 cases, among which $5(12.5 \%)$ developed fistulas: 4 in the nonstenting subgroup (14.8\%) and 1 in the stenting subgroup $(7.7 \%)$. According to a recent classification, 4 fistulas were considered grade $\mathrm{A} ; 1$, grade $\mathrm{B}$; and 0 , grade $\mathrm{C}$. The grade $\mathrm{B}$ patient did not undergo stenting.

Conclusion. Our preliminary experience should prompt more widespread evaluation of the nonclosure technique.

Key words Distal pancreatectomy $\cdot$ Pancreatic fistula $\cdot$ Nonclosure technique . Saline-coupled bipolar electrocautery . Pancreatic stent

\section{Introduction}

Although advances in surgical technique have reduced the operative mortality rate of pancreatic resection to below $5 \%$ in high-volume centers ${ }^{1-7}$ morbidity rates have changed little, ranging from $30 \%$ to $40 \% .^{2-4,6,7}$ Pancreatic fistula after distal pancreatectomy is a main

Offprint requests to: $\mathrm{H}$. Kitagawa

Received: January 20, 2008 / Accepted: February 20, 2008 cause of postoperative morbidity and is associated with numerous further complications, such as intraabdominal abscess, wound infection, sepsis, electrolyte imbalance, malabsorption, and hemorrhage. ${ }^{8}$ Management of the pancreatic remnant after distal pancreatectomy remains a technical challenge. Several surgical resection and closure techniques have been introduced for managing the pancreatic remnant so as to avoid pancreatic fistulas; these include hand-sewn suture techniques, stapled closure techniques, or a combination of both, ${ }^{9-14}$ as well as ultrasonic dissection devices, ${ }^{15}$ pancreaticoenteric anastomosis, ${ }^{16}$ application of meshes, seromuscu$\operatorname{lar}^{17}$ and gastric serosa patches, ${ }^{18}$ or sealing with fibrin glue. ${ }^{19,20}$ However, none of these techniques has been demonstrated to have a firm advantage over others as the optimal technique of pancreatic stump closure. ${ }^{8}$

We developed a new technique for preventing pancreatic fistula after distal pancreatectomy. The distinctive aspect of this technique involves treatment of the cut end of the pancreatic remnant. We employed a nonclosure technique as opposed to the previous closure techniques for managing the cut end of the pancreatic remnant. This technique has two main parts: reliable ligation of the main pancreatic duct, and the sealing of the cut surface by shrinkage induced by lowtemperature coagulation with saline-coupled bipolar electrocautery. Recently, intraoperative stenting of the remnant pancreatic duct has been added.

\section{Surgical technique}

Pancreatic transection and hemostasis

A vascular tape is looped under the transection line of the pancreas after ligation and division of the splenic artery and vein. The pancreatic body proximal to the transection plane is fastened by vascular tape, and the portion distal to the transection plane is ligated with 1-0 
silk. A thin, narrow spatula is passed under the transection line to protect the underlying major vein, and the pancreas is transected sharply with a knife (Fig. 1). The vascular loop is loosened gradually, and hemostasis of the cut edge of the proximal pancreatic remnant is secured. Certain large arterial bleeding points are selectively suture-ligated using 6-0 Maxon (Davis \& Geck, St. Louis, MO, USA) without involving the pancreatic parenchyma (Fig. 2). Bleeding points from many smaller

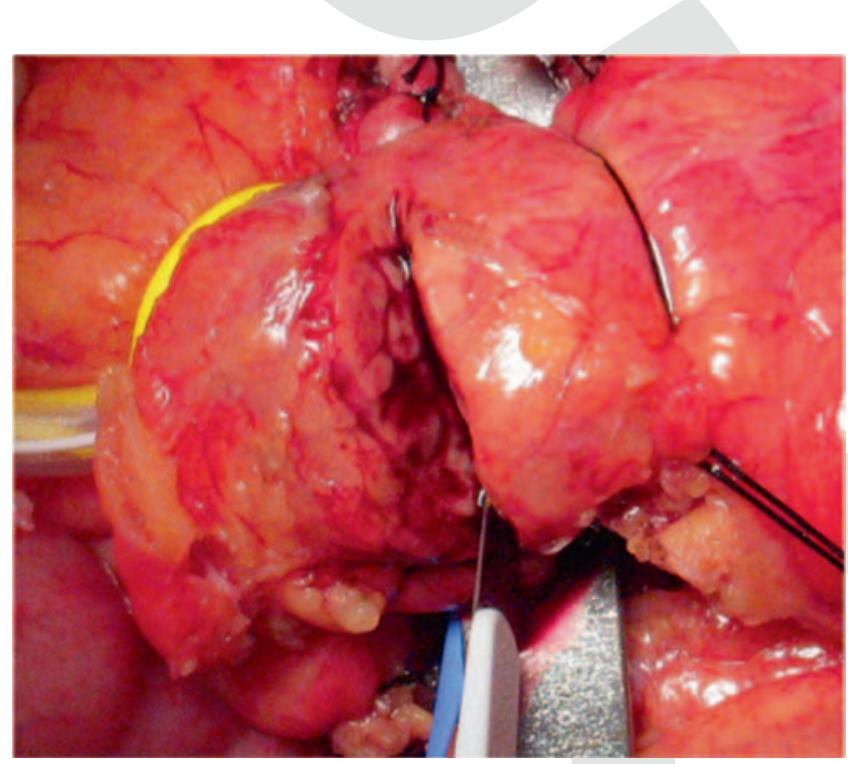

Fig. 1. Transection of the pancreas. The pancreatic body proximal to the transection plane is fastened by vascular tape, and the body distal to the transection plane is ligated with 1-0 silk. A thin, narrow spatula is passed under the transection line to protect the underlying major vein, and the pancreas is transected sharply with a knife
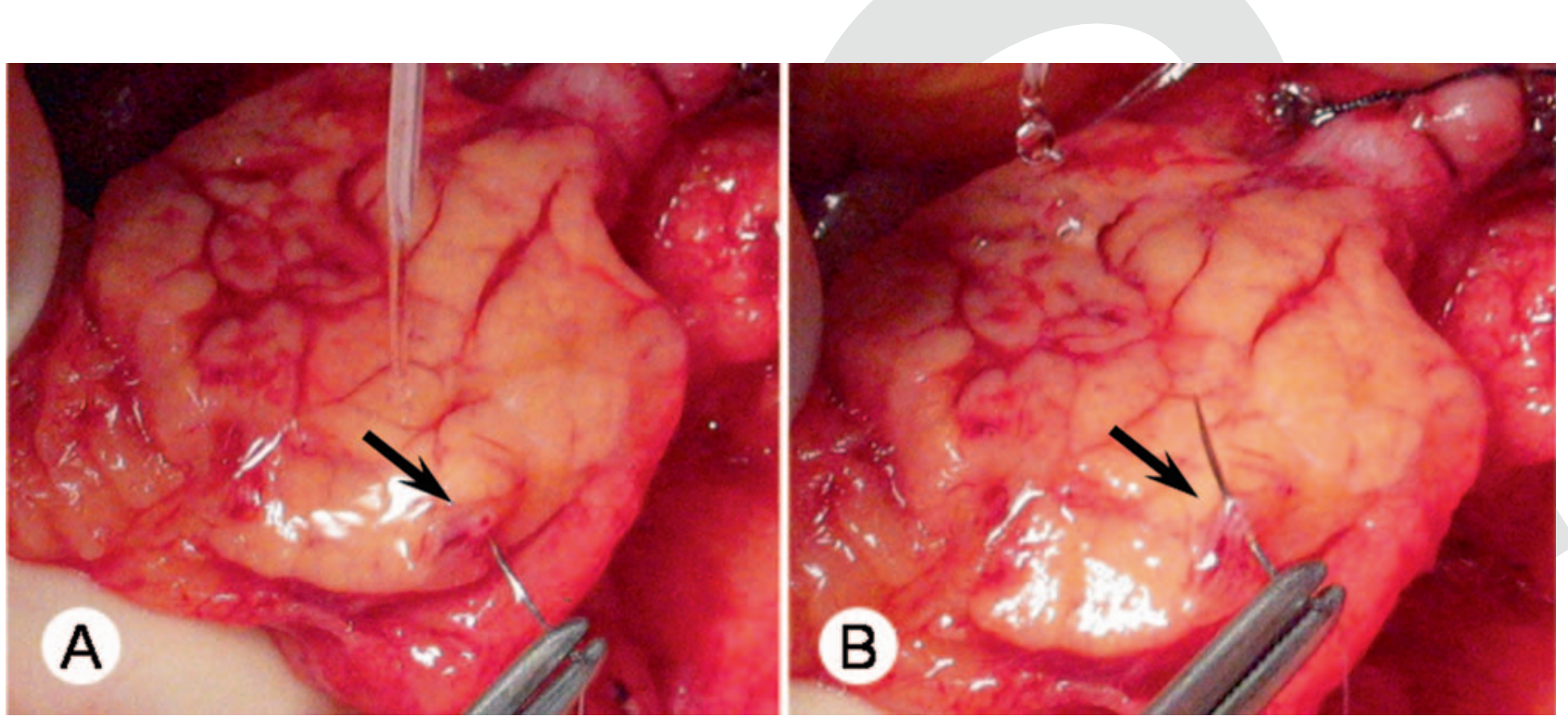

Fig. 2. Arresting arterial bleeding from the cut surface of the pancreas (A). Large arterial bleeding points are selectively sutureligated using 6-0 Maxon (B) without involving the pancreatic parenchyma (arrow) arteries and venous are coagulated carefully using saline-coupled bipolar electrocautery.

\section{Sealing of the cut end of the pancreas with saline-coupled bipolar electrocautery}

Ordinary bipolar electrocautery was modified by addition of an infusion line to carry saline droplets down the inner surface of one arm of the forceps through an opening about $1.5 \mathrm{~cm}$ proximal to its tip, as described by Yamamoto et al. in $1999 .^{21}$ This device was developed for hemostatic sealing and coagulation during hepatic parenchymal transection. Part of its efficacy is related to collagen shrinkage and fusion, which can completely obliterate the lumens of small vessels and ducts. A regular drip infusion line is connected to the inner infusion line, and the rate of saline infusion can be adjusted easily using a flexible clamp.

We usually use an electrosurgical generator setting of $50 \mathrm{~W}$ and a saline drip rate of $0.3 \mathrm{ml} / \mathrm{s}$; when the blades of the forceps are approximated to 1-2 $\mathrm{mm}$, saline droplets are directed to the tip of the forceps where they bubble immediately from heat. The saline facilitates continuous contact with tissue and dispersion of thermal energy, allowing tissue coagulation at a shallower depth than with standard electrical coagulation, while protecting against carbonization and eschar formation by providing heat-coagulative surface cooling and by limiting the temperature to $100^{\circ} \mathrm{C}$. The pancreatic cut surface is sealed at a relatively low temperature, obliterating numerous small cut branches of the pancreatic duct in the cut end together with shrinkage of the pancreatic parenchyma by low-temperature coagulation (Fig. 3). 


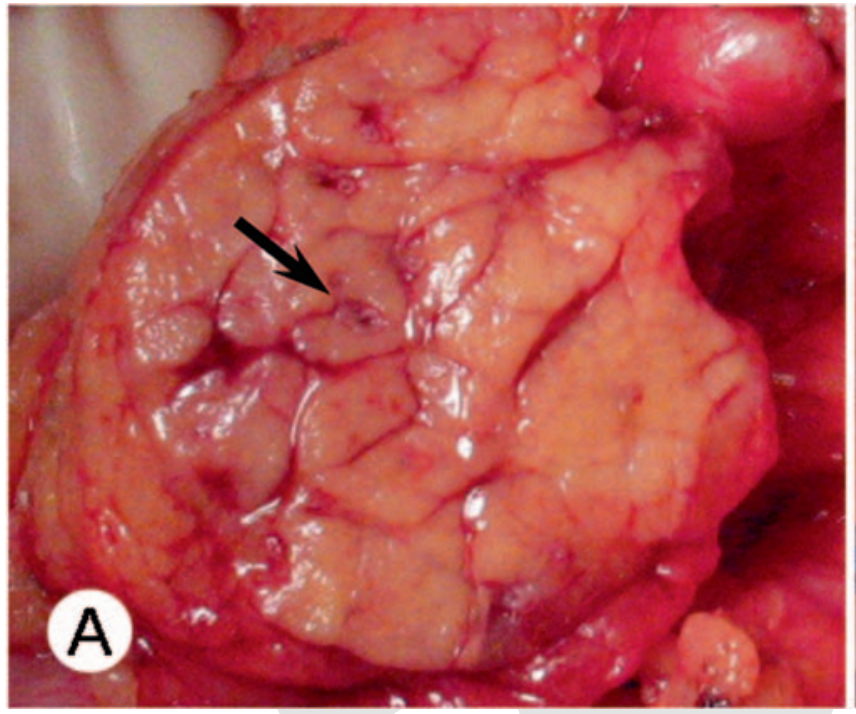

Fig. 3. Sealing of the cut surface of the pancreas with salinecoupled bipolar electrocautery and setting of the pancreatic stenting tube. When the pancreatic cut surface is sealed at low temperature with heated bubbled saline using saline-coupled bipolar electrocautery, numerous small pancreatic ducts at the

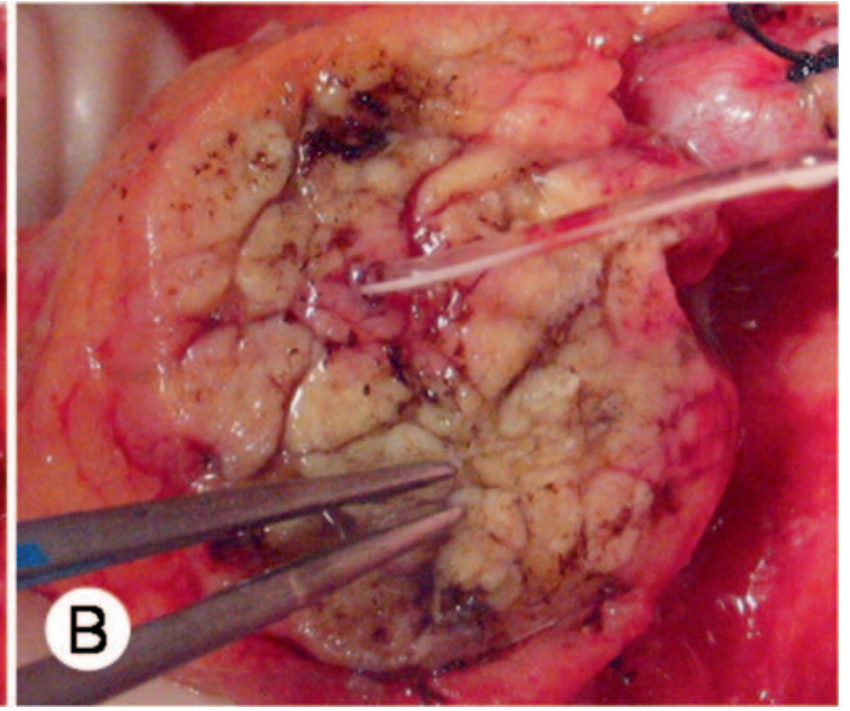

cut surface are sealed together with the shrinkage of pancreatic parenchyma by low-temperature coagulation without carbonization. The surface of the remnant becomes pale and firm (A, pre-; B, post-). Arrow, main pancreatic duct

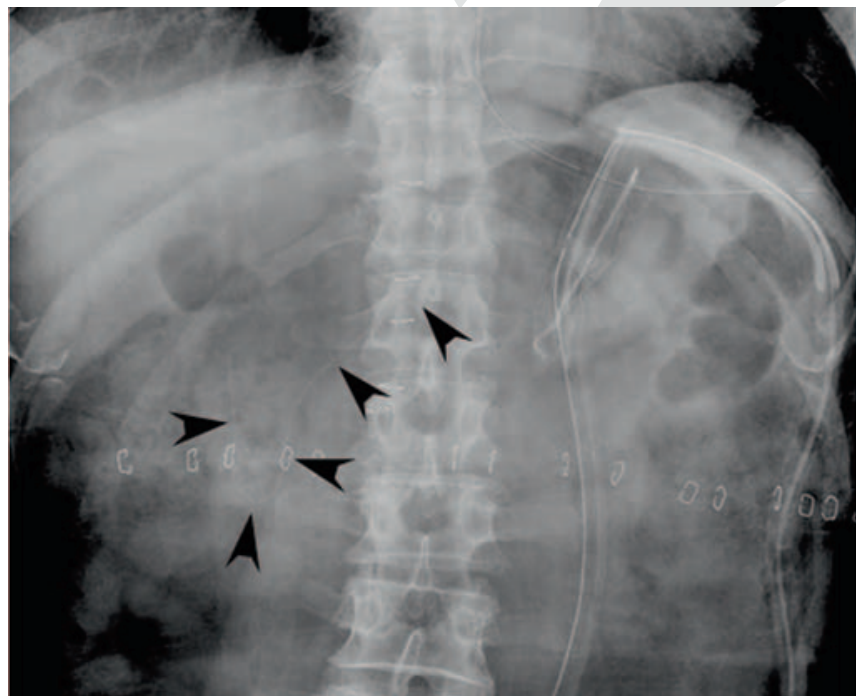

Fig. 4. Placement of the pancreatic stenting tube. A thin stenting tube, usually 3 or 4 Fr. polyethylene tube with multiple side holes every $3 \mathrm{~cm}$, is inserted in the main pancreatic duct from the cut edge of the pancreatic remnant (right).

\section{Placement of the pancreatic stenting tube}

A fine stenting tube, usually a radiopaque 3 or 4 Fr. polyethylene tube with multiple side holes every $3 \mathrm{~cm}$, is inserted into the main pancreatic duct from the cut edge of the pancreatic remnant (Fig. 4). This tube is advanced to a location in the duodenum more than $5 \mathrm{~cm}$ beyond the papilla of Vater, as radiographically confirmed. The tube is expelled spontaneously after oral

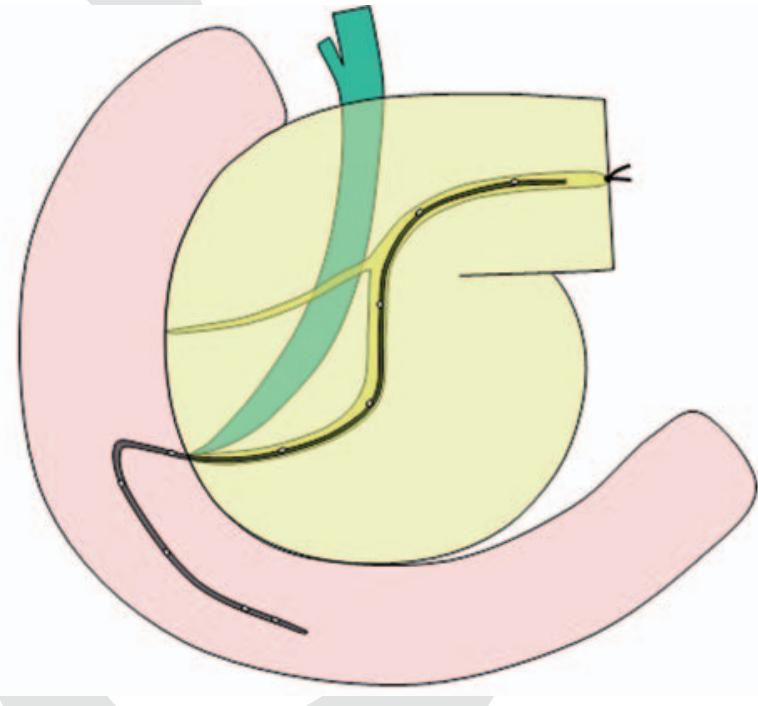

The tube is passed into the duodenum more than $5 \mathrm{~cm}$ from the papilla of Vater, as confirmed radiographically (left; arrowheads)

intake is resumed. This tube provides drainage of pancreatic juice to the duodenum via the papilla of Vater and serves to decompress the main pancreatic duct.

\section{Ligation of the main pancreatic duct}

After insertion of the stenting tube, the main pancreatic duct of the cut surface is anchored by two stay sutures (6-0 Maxon) and traction to protrude the duct about 
$3 \mathrm{~mm}$ from the cut surface, permitting ligation (Fig. 5A). To allow the main pancreatic duct to extend beyond the cut edge, periductal pancreatic parenchyma should be removed carefully. For this maneuver, we usually use a delicate and thin instrument such as the tip of an ordinary monopolar electrocautery electrode (without electricity). Traction is upon the cut end of the main pancreatic duct with the stay sutures, and the duct is ligated with 5-0 Prolene (Ethicon, Hamburg, Germany; Fig. 5B). These manipulations are aided by surgical loupes at $2.5 \times$ magnification. Closure of the cut end of the pancreatic parenchyma is not performed.

\section{Drainage}

Two drainage tubes, one in the splenic fossa (left subphrenic space) and the other in close proximity to the pancreatic transection line, are positioned during the operation. The former is a closed-suction drain (J-VAC silicone drain, 19 Fr., round type; Johnson \& Johnson, Somerville, NJ, USA); the later is a dual-lumen tube (Argyle Salem sump tube, 18 Fr.; Tyco Healthcare, Mansfield, MA, USA) covered with a silicone film drain and suctioned continuously at low pressure $(-10$ to $-15 \mathrm{~cm} \mathrm{H}_{2} \mathrm{O}$ ).

\section{Diagnosis of pancreatic leakage}

For precise diagnosis of pancreatic fistula, the suctiondrainage sump tube is kept near the pancreatic cut end for 2 weeks. Exudate volume and amylase content are measured on alternate days. We defined a pancreatic fistula as secretion of $30 \mathrm{ml}$ or more of amylaserich drainage fluid (>5000 units) per day for more than 10 days, or need for interventional draining of a collection of amylase-rich fluid. ${ }^{22}$ Pancreatic fistulas were graded according to a recent international definition. ${ }^{23}$

Perioperative and postoperative pain management included epidural anesthesia or patient-controlled analgesia in all patients.

\section{Results}

At present, this technique has been used in a total of 40 cases of pancreatic cancer or tumors of the endocrine pancreas. The first 27 operations did not use a stenting tube, while the subsequent 13 did. Pancreatic fistulas developed in 5 cases overall $(12.5 \%)$, with 4 in the unstented subgroup (14.8\%) and 1 in the stented group $(7.7 \%)$. According to the recent fistula definition, 4 fistulas were classified as grade A, 1 as grade $\mathrm{B}$, and none as grade $\mathrm{C}$. The grade $\mathrm{B}$ case was unstented.

\section{Discussion}

Mayo first suggested the possibility of resection of the distal pancreas in $1913,{ }^{24}$ but 44 years passed before Hannon and Sprafka ${ }^{25}$ reported the first successful distal pancreatic resection. Management of the pancreatic remnant following distal pancreatectomy remains an important clinical problem. In particular, pancreatic fistula has resisted prevention by several technical modifications that failed to significantly reduce incidence. ${ }^{14}$ Despite various methods of surgical resection and closure techniques employed in managing the proximal pancreas at distal resection, the fistula rate has been between $8 \%$ and $39 \% .^{14,15,20}$

A recent multivariate analysis concerning pancreatic leakage after left pancreatectomy including clinicopathological and operative factors ${ }^{26}$ indicated that the only variable found to significantly affect likelihood of pancreatic leakage was whether the pancreatic duct was identified and ligated at the time of pancreatectomy. Various closure techniques did not affect occurrence. Indeed, failure to ligate the pancreatic duct was associated with a fivefold increase in risk of leakage compared with duct ligation. ${ }^{9}$ However, even if the pancreatic duct is ligated, pancreatic leakage will occur in $9.6 \%$ of cases and clinically important leakage will occur in $5.5 \%$.

We previously adopted various closure techniques for the cut end of the pancreatic remnant, such as a handsewn suture technique or a stapled closure technique. We sometimes encountered pancreatic fistula, with high-viscosity, brownish discharge via the drainage tube placed near the closed cut end of the pancreatic parenchyma. All pancreatic fistulas were cured by drainage, but hospital stays were prolonged. We hypothesized that pancreatic leakage after duct ligation could result from two factors. One is friability of the ligated portion of the duct caused by reduction of blood supply. Blood supply at the cut end of the pancreas has been found to be an important factor for reducing pancreatic fistula after pancreaticoduodenectomy. ${ }^{27}$ For distal pancreatectomy, the local blood supply at the cut end of the duct is particularly important for ensuring viability of the ligated portion of the pancreatic duct. Some closure techniques will reduce blood supply to the cut end of the pancreatic remnant by compression from strings or staples. Another factor in fistula formation is secretion from numerous small branches of the pancreatic duct at the cut end that no longer communicate with the main pancreatic duct. ${ }^{26,28}$ For focal areas of pancreatic parenchyma near the cut surface, the ducts may be interrupted before they can drain into the main pancreatic duct. Closure techniques cannot completely seal these small branches, leading to persistent extravasation of enzyme-rich pancreatic fluid that bathes the ligated duct and leads to subsequent duct disruption and leakage. ${ }^{29}$ 


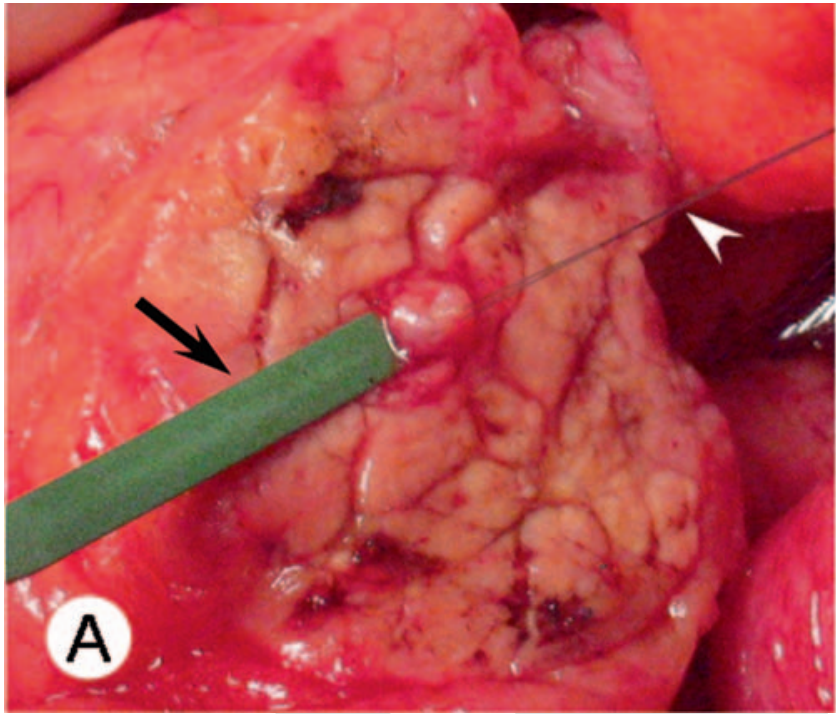

Fig. 5. Protrusion and ligation of the main pancreatic duct. After insertion of the stenting tube, two stay sutures are placed in the main pancreatic duct at the cut surface (6-0 Maxon; white arrowhead, $\mathbf{A}$ ). Traction is applied to protrude the duct about $3 \mathrm{~mm}$ from the cut surface, to facilitate ligation. For protrusion of the main pancreatic duct beyond the cut edge, periductal pancreatic parenchyma should be removed

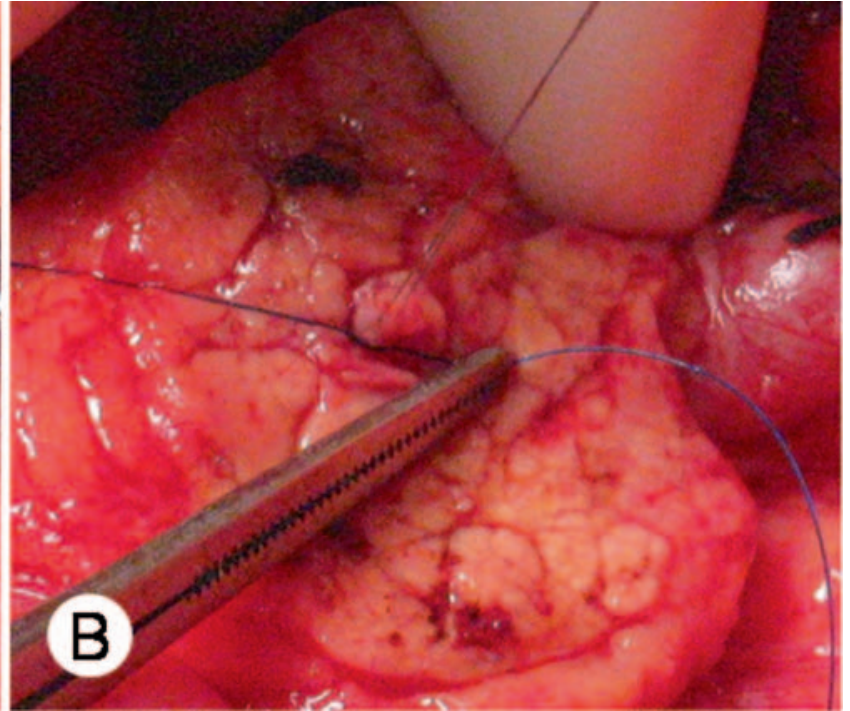

carefully. For this maneuver, we usually use a delicate, thin instrument like the tip of an ordinary monopolar electrocautery electrode (arrow, A). No electricity is delivered (A). Traction is placed upon the cut end of the main pancreatic duct with the stay sutures, and the duct is ligated with 5-0 Prolene (B)

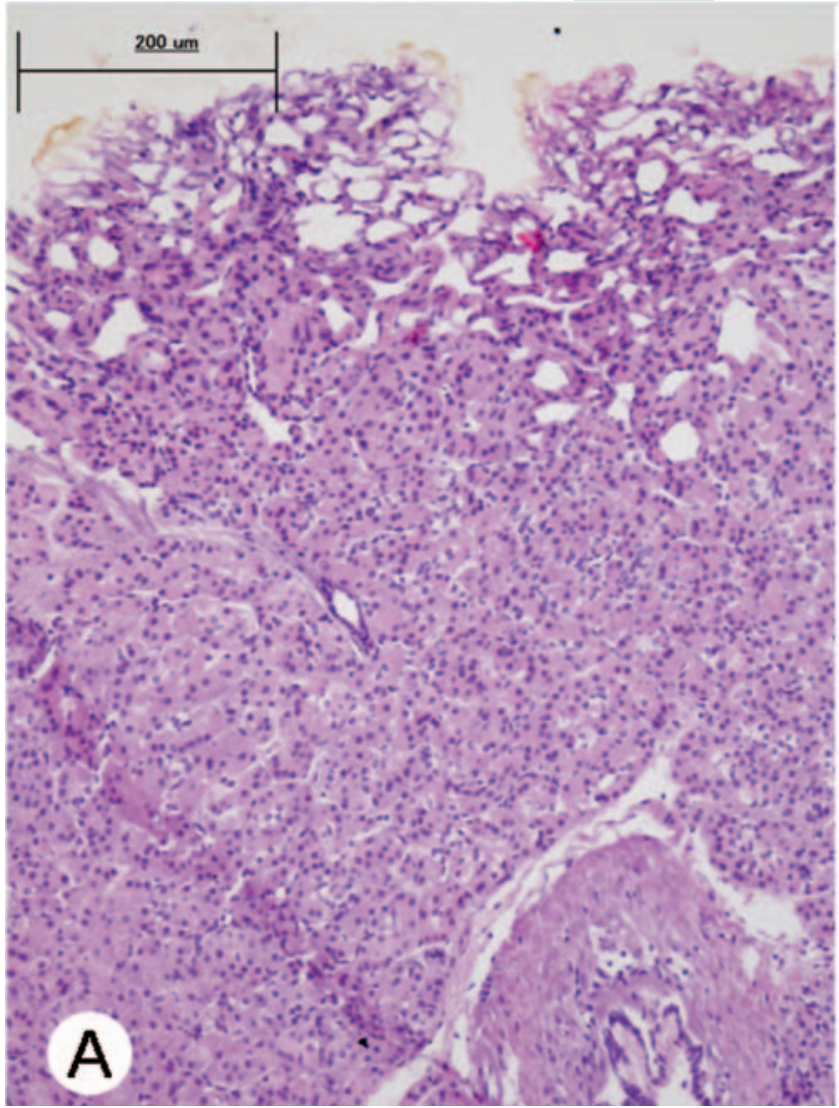

Fig. 6. Histology of the pancreatic stump treated by salinecoupled bipolar electrocautery and by the ordinary monopolar electrocautery. Heat-induced degeneration penetrates to

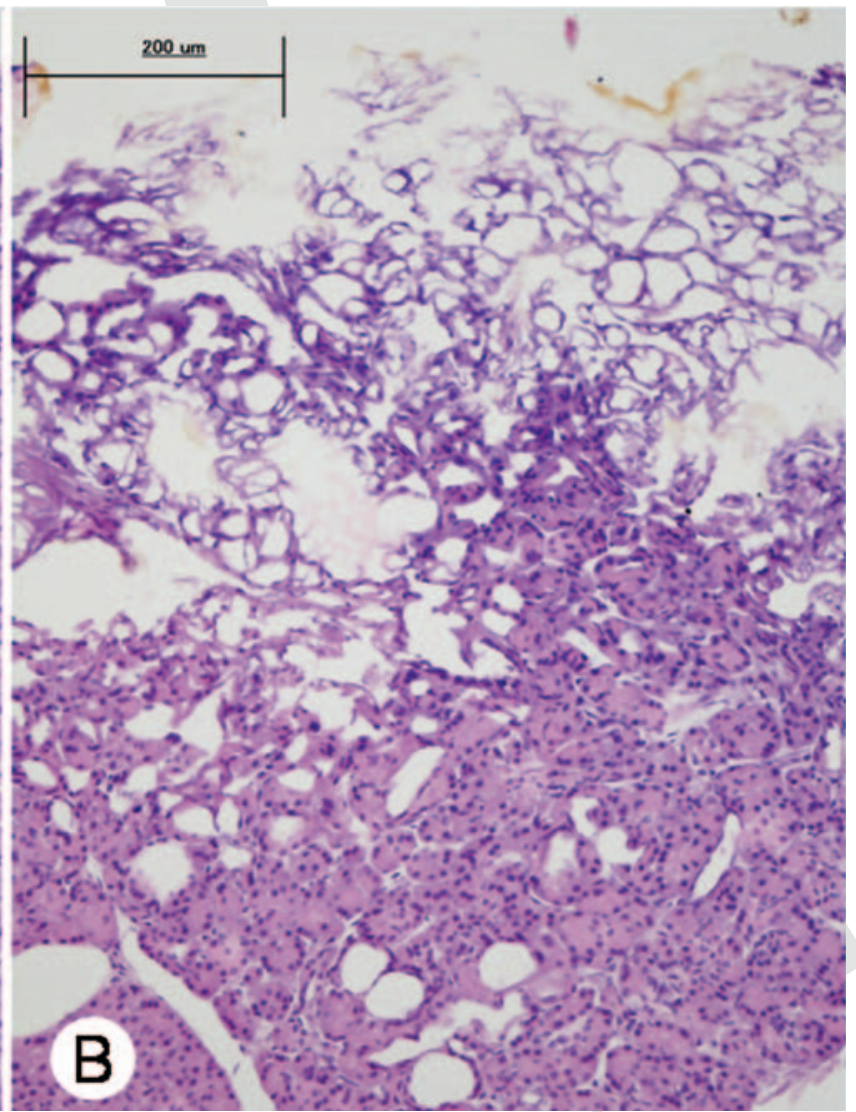

approximately $300 \mu \mathrm{m}$ from the cut end after saline-coupled bipolar electrocautery (A), as compared with $800 \mu \mathrm{m}$ from the cut end for ordinary monopolar electrocautery (B) 
Beginning in 2002, we adopted the nonclosure technique, emphasizing ligation of the main pancreatic duct and coagulation of the cut surface of the pancreatic remnant in a manner that can seal small pancreatic duct branches. Avoiding compression of the parenchyma, this method should not affect the blood supply at the cut end. For consistently reliable ligation, the duct ligation is performed at the inner portion about $3 \mathrm{~mm}$ from the cut end, avoiding heat penetration. We believe that the blood supply of the pancreatic duct should be better at the inner portion than near the cut end, enhancing viability of the ligated portion.

The numerous small branches of the pancreatic duct of the cut surface are sealed along with local shrinkage of pancreatic parenchyma from heat-coagulative surface cooling and limitation of temperature to $100^{\circ} \mathrm{C}$, avoiding carbonization and eschar formation. Because the pancreatic parenchyma contains abundant protein, shrinkage is induced at a low temperature. Heat-induced tissue injury from saline-coupled bipolar electrocautery penetrates only to a depth of $300 \mu \mathrm{m}$ from the cut end according to histopathological examination (Fig. 6A), representing a shallower extent than with ordinary monopolar electrocautery (Fig. 6B). Areas obstructed by sealing most likely develop focal necrotizing pancreatitis, and mucinous brown necrotic discharge sometimes is drained. However, this focal pancreatitis largely abates within a week, and the discharge decreases and ceases rather than progressing to pancreatic fistula.

For preventing the failure of the ligated portion of the pancreatic duct at the cut end, physiological internal pressure of the duct must be maintained. The two possible means accomplishing this include promoting the smooth flow of pancreatic juice without resistance through the papilla of Vater into the duodenum and reducing secretion of pancreatic juice. Beginning in 1985, the endoscopic transpapillary stent placement in the pancreatic duct has been reported to be an effective technique for managing pancreatic pseudocyst or pancreatic duct disruption, and to prevent post-retrograde cholangiopancreatography (post-ERCP) pancreatitis. $^{30-36}$ Although pancreatic stents have received widespread acceptance and application, few data are available concerning their use in perioperative drainage after distal pancreatectomy. ${ }^{37,38}$ The stenting tube acts to maintain physiological internal pressure across lesions or distal to them. These results led us to add intraoperative placement of the pancreatic stenting tube to protect the ligated portion of the pancreatic duct at the cut end after distal pancreatectomy. Stenting should maintain the increased pressure in the pancreatic duct that accompanies contraction of the sphincter of Oddi. In our nonclosure technique, we inserted a narrow stenting tube from the cut edge of the pancreatic remnant across the major papilla. This tube extends into the duodenum for more than $5 \mathrm{~cm}$ beyond the papilla of Vater. With no stay suture, the tube is expelled naturally by peristalsis within 10 days postoperatively (data not shown).

For relaxation of the sphincter muscle of the papilla of Vater, a pasting agent including nitrous acid is used from the day of operation to the 7 th postoperative day. ${ }^{39-41}$ In our series, the pancreatic fistula rate was $12.5 \%$ overall, $14.8 \%$ in the nonstenting group, and $7.7 \%$ in the stenting group. For precise diagnosis of the pancreatic fistula, we periodically collected fluid from the pancreatic cut end via the suction drain for 2 weeks. This method is very sensitive in diagnosis of fistulas compared to methods in some previous reports. Even so, our fistula rate was much lower than with closure techniques such as hand-sewn suture $(50.0 \%)$ or stapled methods $(26.3 \%)$ previously used at our institution.

Our preliminary experience indicates that more widespread evaluation of the nonclosure technique is indicated, particularly by randomized, controlled comparison with other methods. Our department currently is preparing for such a trial.

\section{References}

1. Birkmeyer JD, Siewers AE, Finlayson EV, Stukel TA, Lucas FL, Batista I, et al. Hospital volume and surgical mortality in the United States. N Engl J Med 2002;346:1128-37.

2. Buchler MW, Wagner M, Schmied BM, Uhl W, Friess H, Z'graggen $\mathrm{K}$. Changes in morbidity after pancreatic resection: toward the end of completion pancreatectomy. Arch Surg 2003; 138:1310-4.

3. Cameron JL, Pitt HA, Yeo CJ, Lillemoe KD, Kaufman HS, Colemanet J. One hundred and forty-five consecutive pancreaticoduodenectomies without mortality. Ann Surg 1993;217:430-5.

4. Fernandez-del CC, Rattner DW, Warshaw AL. Standards for pancreatic resection in the 1990s. Arch Surg 1995;130:295-9.

5. van Heek NT, Kuhlmann KF, Scholten RJ, de Castro SM, Busch OR, van Gulik TM, et al. Hospital volume and mortality after pancreatic resection: a systematic review and an evaluation of intervention in the Netherlands. Ann Surg 2005;242:781-8, discussion 788 .

6. Yeo CJ, Cameron JL, Lillemoe KD, Sitzmann JV, Hruban RH, Goodman SN, et al. Pancreaticoduodenectomy for cancer of the head of the pancreas: 201 patients. Ann Surg 1995;221:721-31.

7. Neoptolemos JP, Russell RC, Bramhall S, Theis B. Low mortality following resection for pancreatic and periampullary tumours in 1026 patients: UK survey of specialist pancreatic units. UK Pancreatic Cancer Group. Br J Surg 1997;84:1370-6.

8. Knaebel HP, Diener MK, Wente MN, Buchler MW, Seiler CM. Systematic review and meta-analysis of technique for closure of the pancreatic remnant after distal pancreatectomy. Br J Surg 2005:92:539-46.

9. Bilimoria MM, Cormier JN, Mun Y, Lee JE, Evans DB, Pisters PWT. Pancreatic leak after left pancreatectomy is reduced following main pancreatic duct ligation. Br J Surg 2003;90:190-6.

10. Fahy BN, Frey CF, Ho HS, Beckett L, Bold RJ. Morbidity, mortality, and technical factors of distal pancreatectomy. Am J Surg 2002;183:237-41.

11. Kajiyama Y, Tsurumaru M, Udagawa H, Tsutsumi K, Kinoshita Y, Akiyama H. Quick and simple distal pancreatectomy using the GIA stapler: report of 35 cases. Br J Surg 1996;83:1711. 
12. Sheehan MK, Beck K, Creech S, Pickleman J, Aranha GV. Distal pancreatectomy: does the method of closure influence fistula formation? Am Surg 2002;68:264-7.

13. Takeuchi K, Tsuzuki Y, Ando T, Sekihara M, Hara T, Kori T, et al. Distal pancreatectomy: is staple closure beneficial? Aust N Z J Surg 2003;73:922-5.

14. Balzano G, Zerbi A, Cristallo M, Carlo VD. The unsolved problem of fistula after left pancreatectomy: the benefit of cautious drain management. J Gastrointest Surg 2005;9:837-42.

15. Suzuki Y, Fujino Y, Tanioka Y, Hori Y, Ueda T, Takeyama Y, et al. Randomized clinical trial of ultrasonic dissector or conventional division in distal pancreatectomy for non-fibrotic pancreas. Br J Surg 1999;86:608-11.

16. Adam U, Makowiec F, Riediger H, Trzeczak ST, Benz ST, Hopt UT. Distal pancreatic resection: indications, techniques and complications. Zentralbl Chir 2001;126:908-12.

17. Moriura S, Kimura A, Ikeda S, Iwatsuka Y, Ikezawa T, Naiki K. Closure of the distal pancreatic stump with a seromuscular flap. Surg Today 1995;25:992-4.

18. Kluger Y, Alfici R, Abbley B, Soffer D, Aladgem D. Gastric serosal patch in distal pancreatectomy for injury: a neglected technique. Injury 1997;28:127-9.

19. Ohwada S, Ogawa T, Tanahashi Y, Nakamura S, Takeyoshi I, Ohya $\mathrm{T}$, et al. Fibrin glue sandwich prevents pancreatic fistula following distal pancreatectomy. World J Surg 1998;22: 494-8.

20. Suzuki Y, Kuroda Y, Morita A, Fujino Y, Tanioka Y, Kawamura $\mathrm{T}$, et al. Fibrin glue sealing for the prevention of pancreatic fistulas following distal pancreatectomy. Arch Surg 1995;130: 952-5.

21. Yamamoto Y, Ikai I, Kume M, Sakai Y, Yamauchi A, Shinohara $\mathrm{H}$, et al. New simple technique for hepatic parenchymal resection using a Cavitron Ultrasonic Surgical Aspirator and bipolar cautery equipped with a channel for water dripping. World J Surg 1999;23:1032-7.

22. Buchler MW, Friess H, Wagner M, Kulli C, Wagener V, Z'graggen K. Pancreatic fistula after pancreatic head resection. Br J Surg 2000;87:883-9.

23. Bassi C, Dervenis C, Butturini G, Fingerhut A, Yeo C, Izbicki J, et al. Postoperative pancreatic fistula: an international study group (ISGPF) definition. Surgery (St. Louis) 2005;138:8-13.

24. Mayo WJ. The surgery of the pancreas. Ann Surg 1913;58: 145-50.

25. Hannon DW, Sprafka J. Resection for traumatic pancreatitis Ann Surg 1957;146:136-8.

26. Kleeff J, Diener MK, Z'graggen K, Hinz U, Wagner $M$ Bachmann J, et al. Distal pancreatectomy. Risk factors for surgical failure in 302 consecutive cases. Ann Surg 2007;245:573-82.
27. Strasberg SM, Drebin JA, Mokadam NA, Green DW, Jones KL Ehlers JP, et al. Prospective trial of a blood supply-based technique of pancreaticojejunostomy: effect on anastomotic failure in the Whipple procedure. J Am Coll Surg 2002;194:746-59.

28. Kleitsch WP. Anatomy of the pancreas; a study with special reference to the duct system. AMA Arch Surg 1955;71:795-802.

29. Truty MJ, Sawyer MD, Que FG. Decreasing pancreatic leak after distal pancreatectomy: saline-coupled radiofrequency ablation in a porcine model. J Gastrointest Surg 2007;11:998-1007.

30. Fuji T, Amano H, Harima K, Aibe T, Asagami F, Kinukawa K, et al. Pancreatic sphincterotomy and pancreatic endoprosthesis. Endoscopy 1985;17:69-72.

31. Schneider MU, Lux G. Floating pancreatic duct concrements in chronic pancreatitis. Pain relief by endoscopic removal. Endoscopy $1985 ; 17: 8-10$

32. Kozarek RA, Patterson DJ, Ball TJ, Traverso LW. Endoscopic placement of pancreatic stents and drains in the management of pancreatitis. Ann Surg 1989;209:261-6.

33. Kozarek RA, Ball TJ, Patterson DJ, Freeny PC, Ryan JA, Traverso LW. Endoscopic transpapillary therapy for disrupted pancreatic duct and peripancreatic fluid collections. Gastroenterology 1991;100:1362-70.

34. Barthet M, Sahel J, Bodiou-Bertei C, Bernard JP. Endoscopic transpapillary drainage of pancreatic pseudocyst. Gastrointest Endosc 1995;42:208-13

35. Aizawa T, Ueno N. Stent placement in the pancreatic duct prevents pancreatitis after endoscopic sphincter dilation for removal of bile duct stones. Gastrointest Endosc 2001;54:209-13.

36. Tarnasky PR, Palesch YY, Cunningham JT, Mauldin PD, Cotton PB, Hawes RH. Pancreatic stenting prevents pancreatitis after biliary sphincterotomy in patients with sphincter of Oddi dysfunction. Gastroenterology 1998;115:1518-24.

37. Costamagna G, Mutignani $\mathrm{M}$, Ingrosso $\mathrm{M}$, Vamvakousis $\mathrm{V}$, Alevras P, Manta R, et al. Endoscopic treatment of postsurgical external pancreatic fistulas. Endoscopy 2001;33:317-22.

38. Ukita T, Moriyama A, Tada A, Shimura J, Inoue H, Kakemura $\mathrm{T}$, et al. Successful management of postoperative pancreatic fistula by application of constructed S-type pancreatic stent after operation for abnormal biliary-pancreatic junction. Endoscopy 2003;35:235.

39. Levy A. Coronary impact of dyskinesia of the Oddi sphincter Noxious role of morphine. Salutary action of nitro compounds. Sem Hop 1965;41:418-21.

40. Staritz M, Poralla T, Ewe K, Meyer zum Büschenfelde KH. Effect of glyceryl trinitrate on the sphincter of Oddi motility and baseline pressure. Gut 1985;26:194-7.

41. Luman W, Pryde A, Heading RC, Palmer KR. Topical glyceryl trinitrate relaxes the sphincter of Oddi. Gut 1997;40:541-3. 
AUTHOR QUERY FORM

Dear Author

During the preparation of your manuscript, the questions listed below have arisen. Please answer all the queries by marking any corrections, additions, or deletions on the relevant parts on the proofs as you want the final article to appear.

\begin{tabular}{|l|l|}
\hline $\begin{array}{l}\text { Query } \\
\text { no. }\end{array}$ & Query (Please do NOT reply here.) \\
\hline 1. & AU: please confirm this edit. \\
\hline
\end{tabular}

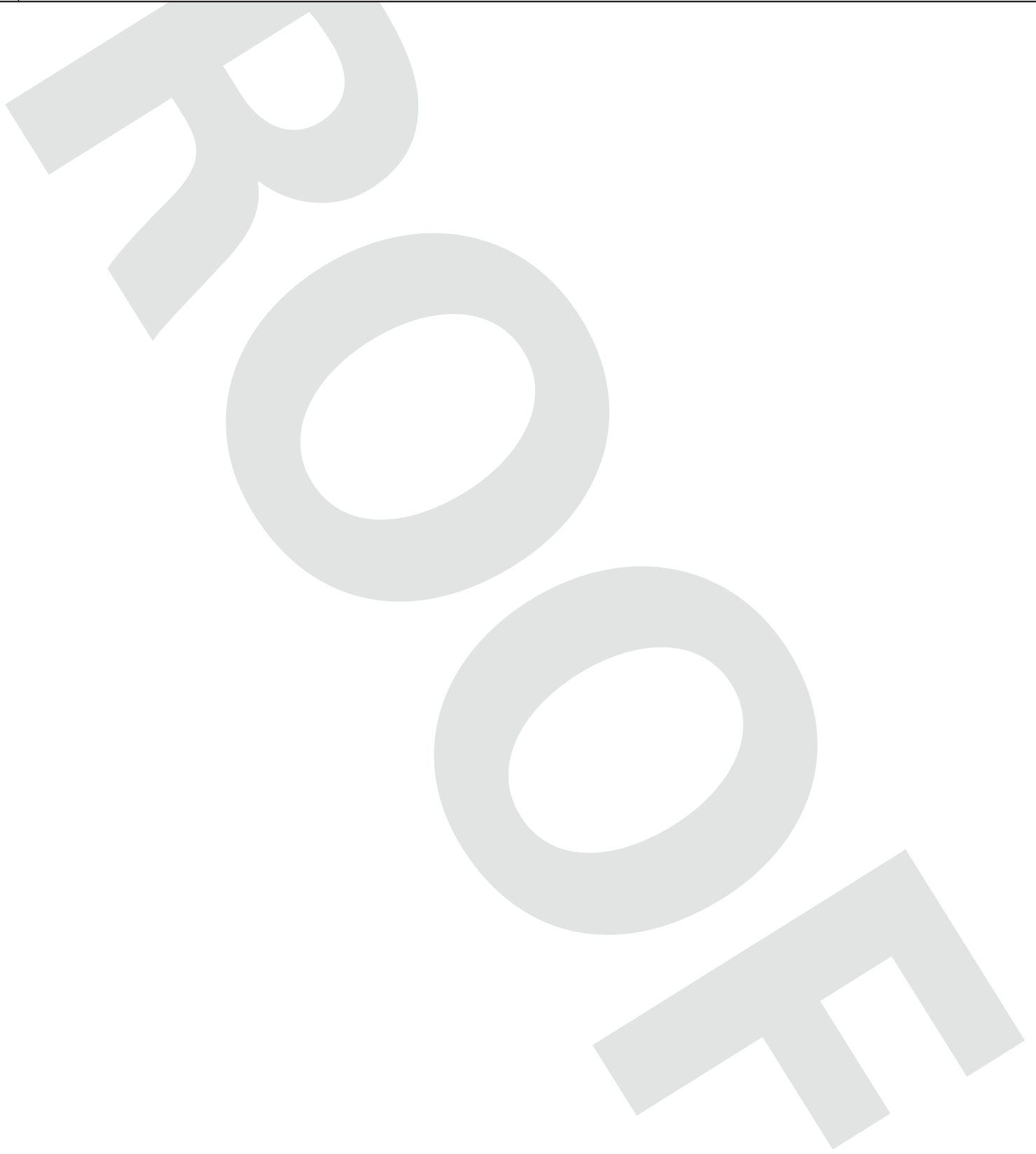

HBP1332

HBP1332_AU_Form.indd 1

5/23/2008 7:23:47 PM 